\title{
The Influence of Parents' Social Capital and Previous Entrepreneurial Experience on Entrepreneurial Opportunity Identification
}

\author{
Li-yao Jin*, Jun-xi Jin \\ Chongqing Technology \& Business University \\ Chongqing, China \\ 1542536084@qq.com
}

\begin{abstract}
This article by using the questionnaire survey data, adopt the method of hierarchical regression empirically the parents' social capital and the effects of entrepreneurial opportunity identification, and examines the social security system in the parents the regulating role in the relationship between social capital and entrepreneurial opportunity identification. The results show that the social capital of parents has a significant positive influence on the recognition of entrepreneurial opportunities, and the previous experience has a significant positive influence on the recognition of entrepreneurial opportunities. The negative social security system to adjust their parents the relationship between social capital and entrepreneurial opportunity identification, which have health insurance or pension insurance of the immigrants.
\end{abstract}

Keywords-Previous entrepreneurial experience; Identification of entrepreneurial opportunities; Parents' social capital; Immigration

\section{INTRODUCTION}

The identification of entrepreneurial opportunity is the precondition of entrepreneurship and the process of multiple factors. As a key factor to realize the employment, stability and prosperity of immigrants and the economic and social development of immigrant areas, immigrant entrepreneurship has become an issue that the governments at all levels of our country pay more and more attention to. However, immigrant entrepreneurs of the three gorges reservoir area is given priority to with farmers, lower cultural degree, entrepreneurial social capital is less, the lack of previous experience and real problem become migrant entrepreneurs find valuable business opportunities.

At present, the research on immigrant entrepreneurship in domestic academic circles mainly focuses on the current situation, basic characteristics and existing problems of immigrant entrepreneurship[1] in hydro-power reservoir area, and the influencing factors of immigrant entrepreneurial decision-making[2]. Foreign scholars mainly study immigrant entrepreneurship from the perspectives of immigrant entrepreneurship motivation[3], migrant entrepreneurship selection path[4] and entrepreneurial performance[5]. Through previous research, the existing immigrants entrepreneurship research only analyzes the social capital of entrepreneurial motivation and the influence of route choice, or in order to investigate the influence of immigrant entrepreneurship performance factors. However, social capital also includes family social capital, parents' social capital and other specific types. Especially under the action of involuntary migrants, the migrants themselves sharp decline in social capital and access to information, at this time of immigrant entrepreneurs strong relation network social relation network (family, friends and countrymen) will further play a role. Parents' social capital as a kind of special type "strong relationship", can reduce uncertainty in immigrant entrepreneurship process, increase the likelihood of access to information resource. In addition, immigrant entrepreneurs are mainly farmers[6], the insufficient skills required by immigrants to establish enterprises and the low comprehensive quality of immigrants have become the factors restricting the development of immigrant entrepreneurship.

Therefore, the previous experience of immigrant entrepreneurs is very important for the identification of entrepreneurial opportunities, but from the perspective of previous studies on immigrant entrepreneurship, the empirical relationship between the two is rarely discussed. Main contribution of this article embodied in: First, the social capital of immigrant entrepreneurs distinguish from general social capital, and empirically the parents' social capital of entrepreneurs is an important factor of entrepreneurial opportunity identification. However, which process be constrained by the social security system; Secondly, the empirical test examines the impact of previous experience of immigrant entrepreneurs on the identification of entrepreneurial opportunities, and further expands the research on previous experience related to entrepreneurship. 


\section{THEORY AND HYPOTHESIS}

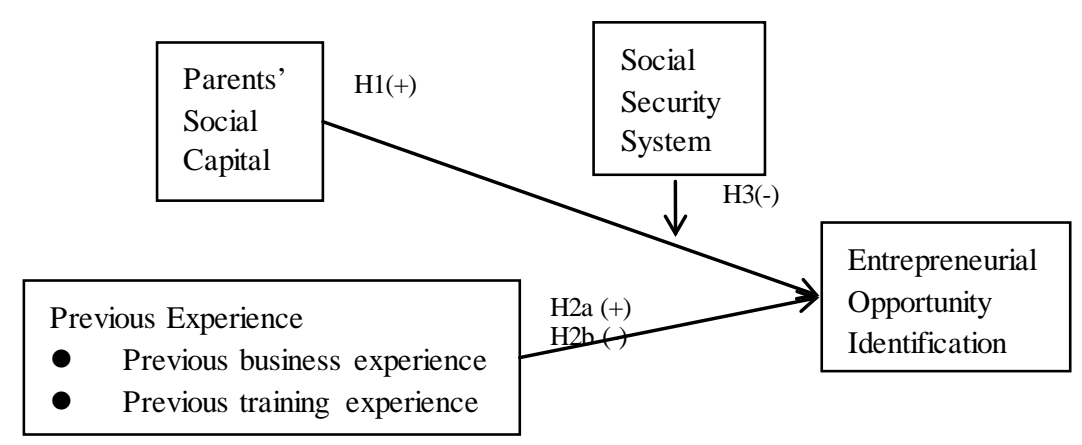

Fig. 1. Research Model

\section{A. The influence of parents' social capital on entrepreneurial opportunity identification}

In the process of identifying opportunities, entrepreneurs must recognize, collect, understand and use information related to specific industries, technologies, markets and policies in some way. The social network of entrepreneurs is a key variable influencing the identification of entrepreneurial opportunities[7]. Granovetter[8] propose that generally considered strong relation network is mainly based on trust and emotion of multiple social relations. It frequent exchanges between the network main body, make the information between resource transfer efficiency is higher. And an immigrant entrepreneurship major group is given priority to with farmers in collectivist culture. Weak network may become an obstacle to the opportunity of cognitive and strong relations has the advantage[9]. In the new entrepreneurial environment, the availability of weak relation network is greatly reduced, and strong relation network will play a greater role. Strong network can greatly shorten the transfer path of innovation resources, improve the level of network knowledge exchange and sharing among the subjects, gave rise to the generation of new ideas and new technology. So through the network of social relations that parents access to information and resources can be easier to excavate and seek business opportunities[10]. In addition, The entrepreneurial experience of parents may subtly influence the entrepreneurial ideas of immigrant entrepreneurs[11]. The social resources accumulated by parents in the early stage have also been transferred to entrepreneurs through "strong relationships", making it an important channel to obtain information on entrepreneurial opportunities. Based on the above analysis, the following hypotheses are proposed: H1: Social capital of parents has a significant positive impact on the identification of entrepreneurial opportunities

\section{$B$. The impact of prior experience on entrepreneurial opportunity identification}

In the previous study, the previous experience mainly included entrepreneurial experience, industrial work experience, management experience, functional experience and training experience. By using previous work experience and previous entrepreneurial experience to examine previous experience, it is found that previous experience positively affects entrepreneurial opportunity identification[12]. As the main group of immigrants and entrepreneurs in the three gorges reservoir area, farmers are generally of low educational level. In the traditional way of life, they do not have much communication with the outside world, and the access to knowledge and information is relatively simple. So the previous entrepreneurial experience and previous training experience of immigrant entrepreneurs is an important factor to improve the ability of entrepreneurial opportunity identification, immigrant entrepreneurs can use the experience accumulated in the previous knowledge to help them find hidden opportunities. First of all, whether it is a failure of entrepreneurial experience or successful entrepreneurial experience will make migrant entrepreneurs and development of the social network was established, to make more entrepreneurial resources, entrepreneurial experience accumulated in the tacit knowledge can help entrepreneurs to make a decision in uncertain environment, thus to find business opportunities, resources and product information[4]. Secondly, the previous entrepreneurial experience also helps to improve the entrepreneur human capital, the increase of human capital can help entrepreneurs to obtain directly the key information resources, and improve the ability of optimal allocation of resources[6]. Then, previous training experience can help entrepreneurs improve their cognitive level, entrepreneurial skills and entrepreneurial alertness, and improve their opportunity identification ability. H2a: The previous entrepreneurial experience of immigrant entrepreneurs has a significant positive impact on the entrepreneurial opportunities identification; H2b: the previous training experience of immigrant entrepreneurs has a significant positive impact on entrepreneurial opportunity identification.

\section{The regulating role of social security system in the identification of social capital and entrepreneurial opportunity}

Many scholars have shown that the establishment and implementation of formal system plays an important role in promoting social development. The immigrant entrepreneurs lag behind the other area since some factors of urban and rural household registration system and labor employment system. In addition, migrant entrepreneurs in the three gorges reservoir area mainly have rural household registration, so the social security system mainly plays a role in pension insurance and 
medical insurance. Due to entrepreneurial activity has certain risk, once in a failed will bring more uncertainty to the immigrant entrepreneurs, so the resettlement area of good stability will increase their living standard and reduces their entrepreneurial intention. For the social security system supports immigrant entrepreneurs, because immigration is forced which make the immigrant entrepreneurs from its own "weak ties" to obtain valuable information in social networks, as a result, their parents' social capital to play a bigger role in entrepreneurial opportunity identification. H3: The social security system in the parents' social capital and entrepreneurial opportunity identification between negative regulatory role.

\section{EMPIRICAL ANALYSIS}

In this paper, data is a questionnaire survey from Da zhou town, Xiao zhou town, Tyrone town, New town, Wulong township and Wanzhou city. In this survey, there are 1004 immigrant questionnaires with entrepreneurial behaviors. As for the measurement of variables, Data is divided by the following measurement indicators and coding rules:

1) Dependent Variables: entrepreneurial opportunity recognition(O-IDEN). The average of the indicators is "you know some new business opportunities, you know the information about the products or services people need, and you know the knowledge and information to improve the existing products or services".

2) Independent Variables: Parents' social capital(PSC) and Previous experience(EN-E,MT-E, PT-E,TR-E). The value of entrepreneurs with entrepreneurial experience is 1 , and that of entrepreneurs without entrepreneurial experience is 0 .

3) Moderator Variable: Social security system(S-SYS). The assignment to buy health insurance or endowment insurance is 1 , and the assignment to not buy health insurance or endowment insurance is 0 .

4) Control Variables: Gender (GEND), Age (AGE), Education degree (EDU), registered permanent residence nature (HK). The male code is 1 and the female code is 0 ; Take the logarithm of the age of the entrepreneur; Primary school and below, middle school, high school (technical secondary school), junior college, undergraduate, and master's degree and above, 1-6 in sequence; after relocation, the agricultural account number is 1 and the urban account number is 0 .

TABLE I. STATIST ICAL ANALYSIS \& CORRELATION COEFFICIENT

\begin{tabular}{|c|c|c|c|c|c|c|c|c|c|c|c|c|c|}
\hline Variable & Average Value & Standard Deviation & 1 & 2 & 3 & 4 & 5 & 6 & 7 & 8 & 9 & 10 & 11 \\
\hline$O-I D E N$ & 3.736 & 1.507 & 1 & & & & & & & & & & \\
\hline PSC & 4.142 & 1.475 & $0.756 * * *$ & 1 & & & & & & & & & \\
\hline$E N-E$ & 1.600 & 0.518 & $0.292 * * *$ & $0.230 *$ & 1 & & & & & & & & \\
\hline MT-E & 1.540 & 0.500 & $0.381 * * *$ & $0.344 * * *$ & $0.290 * *$ & 1 & & & & & & & \\
\hline$P T-E$ & 1.530 & 0.501 & $0.364 * * *$ & $0.409 * * *$ & $0.197^{*}$ & $0.684 * * *$ & 1 & & & & & & \\
\hline$T R-E$ & 1.590 & 0.493 & $0.396 * * *$ & $0.267 * *$ & $0.294 * *$ & $0.486^{* * *}$ & $0.633 * * *$ & 1 & & & & & \\
\hline$S$-SYS & 1.040 & 0.202 & -0.029 & $0.015^{*}$ & -0.078 & 0.045 & 0.035 & -0.056 & 1 & & & & \\
\hline GEND & 1.570 & 0.496 & $-0.200^{*}$ & $0.213^{*}$ & $-0.227^{*}$ & $0.377 * * *$ & $0.165^{+}$ & $0.154^{+}$ & 0.147 & 1 & & & \\
\hline$A G E$ & 1.699 & 0.122 & $-0.104 * * *$ & -0.116 & -0.112 & -0.019 & 0.027 & 0.111 & $-0.178^{+}$ & $-0.201^{*}$ & 1 & & \\
\hline$E D U$ & 2.340 & 1.131 & -0.129 & -0.031 & -0.081 & $-0.170^{+}$ & -0.138 & $-0.187^{*}$ & $0.180^{*}$ & -0.074 & $-0.637 * * *$ & 1 & \\
\hline$H K$ & 1.300 & 0.494 & $-0.195^{*}$ & -0.169 & -0.080 & -0.085 & -0.155 & -0.059 & 0.067 & -0.148 & 0.147 & 0.143 & 1 \\
\hline
\end{tabular}

\section{A. Descriptive statistics and correlation analysis}

TABLE I shows the mean, standard deviation and Pearson correlation coefficients of each variable. In terms of correlation coefficient, there is a significant positive correlation between social capital, previous entrepreneurial experience, previous skill training experience, previous entrepreneurial training experience and entrepreneurial opportunity identification of the parents $(p<0.001)$. This indicates that these factors have a close relationship between entrepreneurial opportunity identification, provides initial evidence for the hypothesis $\mathrm{H} 1, \mathrm{H} 2$.

TABLE II. THE REGRESSION RESULTS OF SOCIAL CAPIT AL OF PARENTS' GENERATION ON THE RECOGNITION OF ENT REPRENEURIAL OPPORT UNITY

\begin{tabular}{lllll}
\hline Variable & MODEL 1 & MODEL 2 & MODEL 3 & MODEL 4 \\
\hline GEND & $0.185(0.120)$ & $-0.001(0.080)$ & $-0.001(0.081)$ & $0.006(0.079)$ \\
AGE & $-0.006(0.005)$ & $-0.003(0.003)$ & $-0.004(0.004)$ & $-0.003(0.003)$ \\
EDU & $-0.120^{+}(0.062)$ & $-0.037(0.040)$ & $-0.037(0.041)$ & $-0.036(0.040)$ \\
$H K$ & $-0.158(0.117)$ & $-0.090(0.077)$ & $-0.089(0.077)$ & $-0.088(0.076)$ \\
PSC & & $0.711^{* * *}(0.040)$ & $0.711^{* * *}(0.040)$ & $0.703^{* * *}(0.039)$ \\
EN-E & & $0.161^{+}(0.105)$ & $0.160^{+}(0.105)$ & $0.186^{+}(0.104)$ \\
MT-E & & $0.339^{*}(0.141)$ & $0.339^{*}(0.141)$ & $0.269^{*}(0.140)$ \\
PT-E & $-0.384^{*}(0.156)$ & $-0.383^{*}(0.157)$ & $-0.330^{*}(0.155)$ \\
TR-E & $0.476^{* * *}(0.133)$ & $0.475^{* * *}(0.133)$ & $0.449^{* *}(0.131)$ \\
S-SYS & & $-0.022(0.187)$ & $-0.083(0.186)$ \\
PSC $\times$ S-SYS & & & $-0.737 * *(0.222)$ \\
\hline
\end{tabular}




\begin{tabular}{lllll}
\hline & \multicolumn{3}{c}{ Cont. to TABLE II } \\
\hline- CONS & $4.235^{* * *}(0.476)$ & $3.172^{* * *}(0.385)$ & $3.174^{* * *}(0.386)$ & $3.180^{* * *}(0.380)$ \\
$\mathrm{R}^{2}$ & 0.037 & 0.600 & 0.600 & 0.615 \\
Adj $^{2}$ & 0.025 & 0.588 & 0.587 & 0.600 \\
$\mathrm{~F}$ & $2.943^{*}$ & $50.066^{* * *}$ & $44.913^{* * *}$ & $43.194^{* * *}$ \\
$\mathrm{~N}$ & 310 & 310 & 310 & 310 \\
Tips $:+\mathrm{p}<0.10,{ }^{*} \mathrm{p}<0.05, * * \mathrm{p}<0.01, * * * \mathrm{p}<0.001$ & & \\
\hline
\end{tabular}

\section{B. Hypothesis testing}

Through hierarchical regression method validation theory hypothesis, this paper use their social capital and the interaction of the social security system to measure, to verify the social security in the parents' social capital and the regulation of immigration asked of entrepreneurial opportunity identification effect. In order to ensure that there is not collinearity problem, the interactive measurement items have been centralized. The test results are shown in TABLE II.

Model 1 is the benchmark model, which only considers the influence of control variables on the opportunity recognition of immigrant entrepreneurs. Model 2 examines the main effect of social capital and previous experience of parents on the opportunity recognition of micro-enterprise entrepreneurs. Model 3-4 the moderating effect of social security system on the relationship between parents' social capital and opportunity recognition. The diagnostic results of variance inflation factor showed that the maximum value of variable VIF was 1.760 , indicating that there was no serious multi-collinearity between variables.

1) The influence of social capital and previous experience of parents on opportunity identification. According to TABLE I, the parents' the social capital have significant positive influence on entrepreneurial opportunity identification ( $\beta=0.161, p<0.10 ; \beta=0.476, p<0.001$ ), which has rich parents' social capital easier to entrepreneurial opportunity identification, hypothesis $\mathrm{H} 1$ verified, which shows that the three gorges reservoir area of immigrant entrepreneurs under the special policy environment, and easier to use the resources to obtain information on the entrepreneurial opportunities.

Previous entrepreneurial experience of immigrant entrepreneurs, entrepreneurship training experience previously have significant positive influence on entrepreneurial opportunity recognition ( $\beta=-0.384, p<0.05)$, previous professional technical training experience has a significant negative effect on entrepreneurial opportunity recognition ( $\beta=0.711, p<0.001$ ), previous management training experiences have significantly positive effects on entrepreneurial opportunity recognition ( $\beta=0.339, p<0.05$ ), hypothesis H2a verified, hypothesis H2b get part of the validation. Possible explanation is that the previous professional technical training experience may help immigrant entrepreneurs in the field of a deepening breadth and depth of knowledge in this field, but it also will curing the framework of the entrepreneurial cognition, which restricted entrepreneurial opportunities information recognition, lead to earlier professional technical training experience negative impact of entrepreneurial opportunity recognition.
2) Social security system plays a moderating role in the relationship between social capital and entrepreneurial opportunity recognition of immigrant entrepreneurs' parents. As can be seen from model 3 and model 4, when the interaction terms between social capital and social security system of the parents enter the model, the interactive measurement of capital and social security system has a significant negative impact on the identification of entrepreneurial opportunities( $\beta=-0.737, p<0.01 \quad$ ). According to the interaction effect of social capital and social security system of parents' generation, the interactive effect diagram is drawn. It indicates that under the effect of the protection of social security system, the immigrant entrepreneurs to parents on the impact of social capital on entrepreneurial opportunity identification is smaller.

\section{CONCLUSION}

As a key factor of immigrant entrepreneurship, entrepreneurial opportunity identification plays a vital role in immigrant entrepreneurship. This paper by using the questionnaire survey data of three gorges immigrants, adopt the method of hierarchical regression empirically the parents' social capital and prior experience the effects of entrepreneurial opportunity identification, and examines the social security system in the parents the regulating role in the relationship between social capital and entrepreneurial opportunity identification. To strengthen the social capital can largely affect entrepreneurial opportunity identification theory, empirically the parents' social capital of immigrant entrepreneurs are the important factors that affect entrepreneurial opportunity recognition. Further enriched and expanded the previous experience of entrepreneurs and entrepreneurial opportunity identification research. From the early stage of the study of previous experience and entrepreneurial opportunity identification, mostly with farmers and small micro enterprise is given priority. For the first time in three gorges reservoir immigrants as an object, the paper discusses the previous experience and the relationship between entrepreneurial opportunity identification, makes up for the blank in the research of this aspect of the group. Social security system was taken into account as a moderating variable, which opened up a new perspective for the study of entrepreneurship.

This paper has certain enlightenment on immigrant entrepreneurial practice and relevant policies: (1) pay attention to the role of parents' social capital in entrepreneurial practice. Immigrant entrepreneurs should make full use of their parents' social capital and other strongly related social networks to acquire valuable resources, accumulate relevant information and knowledge; (2) strengthen the relevant entrepreneurship training, including business knowledge and skills training, to make the immigrant entrepreneurs cognitive level of 
entrepreneurship and entrepreneurial alertness effectively improve; (3) From the perspective of policy makers, the relevant government departments should be aim to reduce the barriers to entry of entrepreneurship, encourage the relevant practice of immigrant entrepreneurs.

\section{REFERENCE}

[1] Wang peipei, xu jiajun. Analysis on the impact of livelihood capital on reservoir migration and entrepreneurship [J]. Population, resources and environment,2013,02:150-156. (In Chinese)

[2] Yang xiaoliang, wang chongju. Research on influencing factors of migrant entrepreneurship decision-making in the three gorges reservoir area [J]. Rural economy,2015,09:120-124. (In Chinese)

[3] Brush C G, Greene P. The entrepreneurial challenge of constructing a resource base[J]. The Academy of Management Executive (1993-2005), 2001, 15(1):64-80.

[4] Ndofor H A. Immigrant entrepreneurs, the ethnic enclave strategy, and venture performance[J]. Journal of Management, 2011, 37(3):790-818.

[5] Chaganti R, Greene P G. Who Are Ethnic Entrepreneurs? A Study of Entrepreneursapos; Ethnic Involvement and Business Characteristics[J]. Journal of Small Business Management, 2010, 40(2):126-143.
[6] Sequeira J M, Rasheed A A. START-UP AND GROWTH OF IMMIGRANT SMALL BUSINESSES: THE IMPACT OF SOCIAL AND HUMAN CAPITAL[J]. Journal of Developmental Entrepreneurship, 2011, 11(04):357-375.

[7] Zhao xihua, zhou shdong. Status quo, influencing factors and countermeasures of farmers' entrepreneurship [J]. Journal of jianghai studies,2006,01:217-222. (In Chinese)

[8] Granovetter M S. The Strength of Weak Ties[M]. 1973.

[9] Zhao haoxing, zhang qiaowen. Study on the impact of human capital on entrepreneurial performance of rural micro-enterprise entrepreneurs [J]. Technological progress and countermeasures, 2013(12): 151-156. (In Chinese)

[10] Guo hongdong, ding gaojie. Identification of social capital, prior knowledge and farmers' entrepreneurial opportunities [J]. Journal of South China agricultural university, 2012(3):78-85. (In Chinese)

[11] Luo mingzhong, huang shasha. Intergenerational factors influencing farmers' entrepreneurial performance[J]. Agricultural economy and management, 2014 (6) : 29-39. (In Chinese)

[12] Zhang yuli, Yang jun, ren bing. Social capital, previous experience and entrepreneurial opportunity-an interactive effect model and its implications [J]. Managing the world, 2008(7):91-102. 